\title{
Preparation, pharmacokinetics, tissue distribution and antitumor effect of sorafenib-incorporating nanoparticles in vivo
}

\author{
XIA SHENG ${ }^{1,2}$, TAO HUANG ${ }^{1}$, JIANMIN QIN ${ }^{1,2}$, QI LI $^{3}$, WEIWEI WANG ${ }^{4}$, LIANDONG DENG $^{4}$ and ANJIE DONG ${ }^{4}$ \\ ${ }^{1}$ Department of General Surgery, The Third Hospital, The Second Military Medical University, Shanghai 201805; \\ ${ }^{2}$ Department of General Surgery, Putuo Hospital; ${ }^{3}$ Department of Medical Oncology, Shuguang Hospital, \\ Shanghai University of Traditional Chinese Medicine, Shanghai 200062; ${ }^{4}$ Institute of Chemical Industry, \\ Tianjin University, Tianjin 300072, P.R. China
}

Received December 25, 2015; Accepted June 2, 2017

DOI: $10.3892 / \mathrm{ol} .2017 .6934$

\begin{abstract}
Sorafenib is a molecularly targeted drug used for treating hepatocellular carcinoma. However, sorafenib may affect the function of normal hepatocytes, and the clinical application of sorafenib is limited due to its adverse effects. The aim of the current study was to improve the effectiveness of sorafenib by preparing it as a nanoparticle formulation using nanoprecipitation technology. Sorafenib was combined with a polyethylene glycol monomethyl ether-racemic polylactic acid copolymer. The properties of the nanoparticles, including particle size, $\xi$ potential and release efficiency, were measured. The pharmacokinetic profile, tissue distribution and tumor-inhibiting effects of the nanoparticles were determined in vitro and in vivo. Compared with sorafenib, the nanoparticle formulation exhibited a significant increase in in vivo retention time. The concentration of sorafenib in tumor tissues was significantly higher than that in normal tissues following treatment with sorafenib nanoparticles. Sorafenib nanoparticles were more efficacious in inhibiting tumor growth compared with sorafenib alone. The results, provided they can be extended to humans, suggest that sorafenib nanoparticles may specifically target hepatocellular carcinoma.
\end{abstract}

\section{Introduction}

Hepatocellular carcinoma (HCC) ranks fifth for newly diagnosed malignant tumors and is the third leading cause of cancer-associated mortality worldwide in 2001 (1). In China, it is the second most common type of malignant tumor, associated with 564,000 newly diagnosed cases and 549,000 reported mortalities annually (2). The overall 5-year survival rate of

Correspondence to: Dr Jianmin Qin, Department of General Surgery, The Third Hospital, The Second Military Medical University, 700 North Moyu Road, Jiangding, Shanghai 201805, P.R. China

E-mail: jianminqin@yahoo.com

Key words: sorafenib, nanoparticle, target, liver cancer
HCC is $<5 \%$ (2). The portal vein is prone to HCC invasion, leading to intrahepatic dissemination, resulting in intrahepatic metastasis and a high disease recurrence rate (3). The 5-year metastasis and recurrence rate is reported to be $61.5 \%$ for early-diagnosed cases subsequent to radical resection and 43.5\% for subclinical HCCs, significantly affecting the treatment outcome (3). Systemic or local chemotherapy following surgery may improve the survival rate to an extent; however, the clinical use of chemotherapeutic drugs is restricted by their low specificity, leading to severe adverse effects, including toxicity in the heart, lungs and kidneys.

Recent studies have indicated that the activation of the Raf/mitogen-activated protein kinase kinase 1 $(\mathrm{MEK}) /$ mitogen-activated protein kinase 1 (ERK) pathway serves a pivotal role in regulating HCC proliferation (4). Sorafenib is an inhibitor of serine/threonine and tyrosine kinases. Sorafenib's antitumor activity results from the downregulation of Ras oncogene activity, which activates the Raf/MEK/ERK pathway to promote the proliferation of tumor cells. Sorafenib, a novel multi-targeted drug, has two antineoplastic mechanisms: i) The direct inhibition of the Ras/Raf/MEK/ERK signaling pathway; ii) the indirect blockade of tumor angiogenesis via the downstream inhibition of vascular endothelial growth factor receptor (VEGFR)-2/platelet-derived growth factor receptor (PDGFR)- $\beta$ (5). However, sorafenib produces certain adverse effects, including diarrhea (8\%), hypertension (2\%), abdominal pain (2\%) and hand-foot skin reactions (HFSR) (6). For example, Luo et al (7) reported that the incidence of HFSR was $74.5 \%$ for sorafenib, with the incidences of grade 1,2 and 3 severity being $52.9,21.6$ and $21.6 \%$, respectively. Chu et al (8) reported that the incidences of grade 1-3 and grade 3 HFRS were 38.8 , and $8.9 \%$, respectively. It is possible that the inhibitory effects produced by sorafenib on the PDGFR and Raf signaling pathways may disrupt the proliferation and repair of normal cells and the blood supply to relevant tissues (9-11). The inability of HCC patients to tolerate adverse effects often leads to a reduction in the dose of sorafenib or the cessation of its use, thereby diminishing its efficacy. Additionally, as sorafenib is insoluble in water, only oral formulations are available at present. As a result, it is important to improve the specificity of binding between sorafenib and HCC cells in 
order to increase its local accumulation in tumors, prolong its functional activity and minimize its side effects on non-tumor hepatic cells and other tissues.

To achieve these aims, the development of sorafenib-incorporating nanoparticles using nanotechnology is reported in the present study.

\section{Materials and methods}

Materials. Sorafenib was purchased from Bayer AG (Leverkusen, Germany). Polyethylene glycol (PEG), polylactic acid, dichloromethane, stannous octoate, rac-lactide, tetrahydrofuran and methanol were provided by Xinhua Chemical Engineering Co., Ltd. (Jiande, China). Cell Counting kit- 8 (CCK-8) was obtained from Sigma-Aldrich (Merck KGaA, Darmstadt, Germany).

A total of 33 ICR mice (male; 4 weeks old, 18-22 g) and 36 Sprague-Dawley (SD) rats (male; 10 weeks old, 300-400 g) were obtained from Shanghai Bikai Experimental Animal Center [Shanghai, China; license no. SCXK (Hu) 2008-0016]. All animals were quarantined for 1 week prior to the start of the experiment. They were housed in an animal facility maintained with a $12 \mathrm{~h}$ light/dark cycle, at a constant temperature of $23 \pm 1^{\circ} \mathrm{C}$ and humidity of $44 \pm 5 \%$, and had free access to water and food. The experimental protocols were reviewed and approved by the Committee of Ethics on Animal Experiments of the Shanghai Bikai Experimental Animal Center, and all animal work procedures were approved by the Institutional Animal Care and Use Committee of Shanghai University of Traditional Chinese Medicine (Shanghai, China).

The H22 mouse HCC cell line was provided by the Shanghai Institutes for Cell Biology, Chinese Academy of Sciences (Shanghai, China). RPMI-1640 culture medium and $10 \%$ fetal bovine serum was purchased from Sigma-Aldrich (Merck KGaA). The H22 mouse HCC cell line was cultured in $5 \% \mathrm{CO}_{2}$ at $37^{\circ} \mathrm{C}$.

Synthesis of PEG monomethyl ether-racemic polylactic acid (mPEG-PDLLA) block copolymer. Ring-opening polymerization was used to synthesize $\mathrm{mPEG}$-co-PDLLA block copolymers. Melted mPEG was placed in a Schlenk tube (Shanghai Heqi Glassware Co., Ltd., Shanghai, China) and vacuum-dehydrated. Refined DLLA and a stannous octoate catalyst (Sigma-Aldrich; Merck KGaA) were added into the tube and vacuumized three times. Nitrogen (Shanghai Jiaya Chemical Co., Ltd., Shanghai, China) was introduced and the tube was vacuumized, sealed and incubated in a $140^{\circ} \mathrm{C}$ oil bath for $10 \mathrm{~h}$. At the end of the reaction, the product was extracted using dichloromethane and cold ether precipitation. mPEG-PDLLA block copolymers were obtained subsequent to vacuum drying.

Preparation of sorafenib-incorporated nanoparticles. Nanoprecipitation was used to prepare sorafenib nanoparticles. Firstly, $250 \mathrm{mg}$ of mPEG-PDLLA of block copolymer and $12.5 \mathrm{mg}$ sorafenib were dissolved in a mixture of $12 \mathrm{ml}$ tetrahydrofuran and $6 \mathrm{ml}$ methanol. The solution was agitated with an automatic agitator until it became transparent. The solvent was removed by vacuum rotary evaporation at $60^{\circ} \mathrm{C}$ and $50 \mathrm{ml}$ distilled water at $60^{\circ} \mathrm{C}$ was added. The water was rotary-evaporated at atmospheric pressure for $10 \mathrm{~min}$ and the supernatant was collected by centrifugation $\left(2,504 \mathrm{x} \mathrm{g}\right.$ at $4^{\circ} \mathrm{C}$ for $\left.10 \mathrm{~min}\right)$ to obtain a solution of sorafenib nanoparticles. Finally, the particle size and $\zeta$ potential were measured using the Nano-ZS ZEN3600 apparatus (Malvern Instruments China, Shanghai, China); the drug-loading amount and drug-embedding ratio were measured with an ultraviolet spectrophotometer. Sorafenib acetonitrile solution $(0.01 \mathrm{mg} / \mathrm{ml})$ was prepared as the control solution. A total of $0.1 \mathrm{ml}$ of sorafenib nanoparticle concentrate was added to $5 \mathrm{ml}$ acetonitrile, and the concentrate was ultrasonicated for $5 \mathrm{~min}$ to fully extract the sorafenib. Then, acetonitrile was added to make up the volume to $10 \mathrm{ml}$. Subsequent to being shaken and centrifuged at $8,452 \mathrm{x}$ g at $4^{\circ} \mathrm{C}$ for $20 \mathrm{~min}$, the supernatant was collected to measure the UV absorption at $263 \mathrm{~nm}$ wavelength, and the absorbance A2 was recorded. The UV absorption of the control solution was measured at a wavelength of $263 \mathrm{~nm}$, and the absorbance (As) was recorded.

The release efficiency using in vitro dialysis methods. The dialysis bags were placed in distilled water for $24 \mathrm{~h}$. A total of $8 \mathrm{ml}$ sorafenib nanoparticle suspension was put into the dialysis bags, the ends of the dialysis bags were clipped, and the bags were placed into the release medium with magnetic stirring $(31 \mathrm{xg})$. Of the solution, $1.0 \mathrm{ml}$ was sampled at $0,0.5$, $1,2,4,8,12,24,36,48$, and $60 \mathrm{~h}$, with $20 \mu \mathrm{l}$ of this sample used to measure the sorafenib content.

The inhibition effect of tumor growth by sorafenibincorporated nanoparticles. A total of four experimental groups were utilized in the present study: Group I, RPMI-1640 culture medium alone (Merck KGaA, Darmstadt, Germany); group II, blank-loaded nanoparticles (6.9, 13.8 and 20.8 $\mu \mathrm{mol} / \mathrm{l})$; group III, sorafenib $(6.9,13.8$ and $20.8 \mu \mathrm{mol} / \mathrm{l})$; group IV, sorafenib nanoparticles $(6.9,13.8$ and $20.8 \mu \mathrm{mol} / \mathrm{l})$. RPMI-1640 culture medium was used as dilution solvent. H22 HCC cells $\left(5 \times 10^{8} / 1\right)$ were seeded into plates and cultured on the condition of $5 \% \mathrm{CO}_{2}$ at $37^{\circ} \mathrm{C}$, then the $\mathrm{H} 22 \mathrm{HCC}$ cells were incubated with the RPMI-1640 culture medium plus blank-loaded nanoparticles, sorafenib or sorafenib nanoparticles groups in vitro at $37^{\circ} \mathrm{C}$ for $48 \mathrm{~h}$. The optical density (wavelength $280 \mathrm{~nm}$ ) was measured by an ELISA reader following incubation with CCK-8 $(20 \mu \mathrm{l} /$ well $)$ for $2 \mathrm{~h}$ at $37^{\circ} \mathrm{C}$. The growth inhibition rate was calculated as follows: (OD control group - OD observation group)/OD control group x $100 \%$.

Pharmacokinetic studies of sorafenib-incorporated nanoparticles in vivo. The SD rats were randomly divided into the sorafenib group (S) and the sorafenib-incorporated nanoparticle group (SNP), with three mice per group. The agents were injected via the tail vein at a dose of $20 \mathrm{mg} / \mathrm{kg}$. Blood samples $(0.5 \mathrm{ml}$ of each rat at per time point) were collected into anticoagulant tubes from caudal veins at 5, 15, 30, 45 and $60 \mathrm{~min}$, and at 2, 4, 8, 12, 24, 36 and $48 \mathrm{~h}$ following the injection. Plasma was aspirated into cryo tubes and stored at $4^{\circ} \mathrm{C}$. A 3200Q-Trap tandem mass spectrometer (Applied Biosystems; Thermo Fisher Scientific, Inc., Waltham, MA, USA) was then used to detect the concentrations of sorafenib in blood plasma at each time point. Pharmacokinetic parameters of the three drugs [elimination constant, half-life $\left(\mathrm{T}_{1 / 2}\right)$ ], area under the curve $(\mathrm{AUC})_{0-48 \mathrm{~h}}, \mathrm{AUC}_{\mathrm{inf}}$, volume of distribution, serum 
clearance and concentration/time at $\max$ ) were calculated using Drug and Statistics Software version 1.2 (Mathematical Pharmacology Professional Committee of China, Shanghai, China).

Establishment of a HCC orthotopic transplantation model in mice. HCC cells in the logarithmic growth phase were cultured in RPMI-1640 medium and prepared in a cellular suspension $\left(1 \times 10^{7} / 1\right)$ that was subcutaneously inoculated at a volume of $0.5 \mathrm{ml}$ into the hind limbs of $3 \mathrm{ICR}$ mice in order to produce a mass. After three weeks, when the size of the mass in each mouse reached $1 \mathrm{~cm}$ in diameter as measured by vernier caliper, the mice were sacrificed by exsanguination under deep isoflurane anesthesia (2\% isoflurane, in a sealed glass container) and the entire mass was resected en bloc and cut into $2 \mathrm{x} 1 \mathrm{x} 1 \mathrm{~mm}$ sections.

Additionally, 30 ICR mice were anaesthetized with $60 \mathrm{mg} / \mathrm{kg}$ of $1 \%$ pentobarbital sodium intraperitoneally. Following the disinfection of the supine abdominal skin, a $1-\mathrm{cm}$ incision of the upper abdomen was made to expose the left lateral lobe of the liver. Tumor tissue from the first group of mice was implanted into the liver parenchyma in the left lateral lobe and the abdominal incision was closed using $2 / 0$ silk. Following surgery, the mice were allowed free access to water and a standard rodent diet.

Biodistribution and antitumor effects of sorafenibincorporated nanoparticles in mice. The size of the HCC mass in tumor-bearing mice was determined by abdominal ultrasonography. When the tumor size reached $1 \mathrm{~cm}$ in diameter, the tumor-bearing mice were assigned randomly into three groups: Normal saline group; sorafenib group, $100 \mathrm{mg} / \mathrm{kg} / \mathrm{day}$ by gastric perfusion; sorafenib-incorporating nanoparticles group, $100 \mathrm{mg} / \mathrm{kg} /$ day via the tail vein. A total of 10 mice were allocated into each group. Following three weeks of treatment, the mice were sacrificed by exsanguination under deep isoflurane anesthesia, and the heart, lungs, muscles, spleen, tumor and peritumor liver tissues were harvested to determine the drug distribution and concentrations in vivo. The weight-volume ratio was adjusted to 1:2 with distilled water. Following homogenization, $100 \mu 1$ homogenate was obtained and vortexed with $10 \mu \mathrm{l}$ internal standard (loratadine, $100 \mathrm{ng} / \mathrm{ml}$ ) and $400 \mu \mathrm{l}$ acetonitrile. Subsequent to centrifuging at $11,739 \mathrm{x} g$ at $4^{\circ} \mathrm{C}$ for $3 \mathrm{~min}$, the supernatant was transferred into sampling tubes to measure the concentration of nanoparticles in tissues using a 3200Q-Trap tandem mass spectrometer. The length and width of the HCC masses were also measured. The tumor tissues were fixed in methanol for $24 \mathrm{~h}$, dehydrated in ethanol and embedded in paraffin for pathological examination.

The formula $V=a \times b^{2} / 2$ was used to calculate the volume of HCC ( $V$, volume; $a$, length; $b$, width). The extent of necrosis was stratified into 3 levels, according to the extent of necrosis: Mild, $\leq 30 \%$; moderate, $>30-\leq 70 \%$; severe, $>70 \%$. The tumor inhibitory rate $(\%)=\left(1-V_{\text {oberservation }} / V_{\text {control }}\right) \times 100 \%$ was used to describe the antitumor effect of the drugs.

Statistical analysis. All data are expressed as the mean \pm standard deviation. Measurement data (sorafenib concentration in blood and tissues) were compared using one-way analysis of variance. Other data were compared using the $\chi^{2}$ test. Statistical analyses

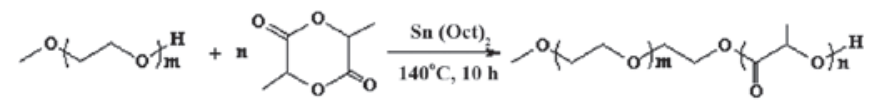

Figure 1. Formula of the mPEG-PDLLA block copolymer. $m=45-46$, $\mathrm{n}=15-16$. PEG, polyethylene glycol.

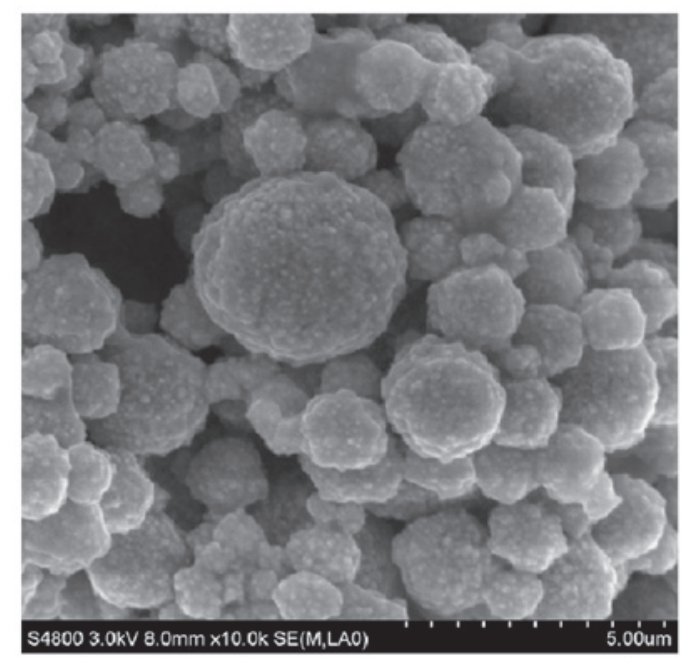

Figure 2. Scanning electric microscopy revealed that sorafenib nanoparticles were of uniform, spherical shape (magnification, x10,000).

were performed using SPSS software version 15.0 (SPSS, Inc., Chicago, IL, USA). $\mathrm{P}<0.05$ was considered to indicate a statistically significant difference.

\section{Results}

Synthesis of mPEG-PDLLA block copolymer. The mPEGPDLLA block copolymer was synthetized by ring-opening polymerization for use as a drug carrier. The mPEG-PDLLA block copolymer demonstrated highly stable chemical and physical properties. The $m$ value range was $45-46$ and $n$ value range 15-16 (Fig. 1).

Physical and chemical properties. Sorafenib nanoparticles exhibited a spherical shape and uniform size (Fig. 2) with a mean particle size of $127.3 \pm 2.0 \mathrm{~nm}$ (Fig. 3) and a $\xi$ potential of $-3.35 \pm 0.42 \mathrm{mV}$. The drug loading value was $6.5 \pm 0.2 \%$; the encapsulation efficiency was $95 \pm 3.2 \%$.

Release kinetics of sorafenib-incorporated nanoparticles in vitro. Release of sorafenib was complete within $8 \mathrm{~h}$, while sorafenib-incorporating nanoparticles exhibited a relatively improved delayed-release effect. The cumulative release rates were 50.91, 56.24, 60.26 and $63.28 \%$ at 24, 48, 72 and $96 \mathrm{~h}$, respectively, following the administration of the nanoparticles (Fig. 4).

Growth inhibitory effects of sorafenib-incorporated nanoparticles on HCC cells. There was no significant inhibition on the proliferation of $\mathrm{H} 22 \mathrm{HCC}$ cells at $48 \mathrm{~h}$ in the RPMI-1640 culture medium and mPEG-PDLLA block copolymer groups. No statistical significance was identified between the RPMI-1640 culture medium group and mPEG-PDLLA 
Table I. In vitro growth inhibitory effect of sorafenib nanoparticles on $\mathrm{H} 22 \mathrm{HCC}$ cells (mean values \pm standard deviation, $\mathrm{n}=3$ ).

\begin{tabular}{lrcc}
\hline & \multicolumn{3}{c}{ Sorafenib, $\mu \mathrm{mol} / 1$} \\
\cline { 2 - 4 } $\begin{array}{l}\text { Treatment, } \% \\
\text { inhibition }\end{array}$ & \multicolumn{1}{c}{6.9} & 13.8 & \multicolumn{1}{c}{20.8} \\
\hline $\begin{array}{l}\text { Sorafenib } \\
\text { Sorafenib } \\
\text { nanoparticles }\end{array}$ & $31 \pm 3.64$ & $30.32 \pm 3.37$ & $30.25 \pm 2.81$ \\
\hline
\end{tabular}

${ }^{\mathrm{a}} \mathrm{P}<0.05$ compared with sorafenib. ${ }^{\mathrm{b}} \mathrm{P}<0.05$ compared with $6.9 \mu \mathrm{mol}$ nanoparticles.

block copolymer groups. The growth inhibitory effect on the H22 HCC cells in the sorafenib-incorporating nanoparticle group was significantly enhanced compared with the RPMI control group $(\mathrm{P}<0.05)$. An upward trend in the growth inhibitory effect with the increase of drug concentration indicated the dose-dependent properties of the nanoparticles $(\mathrm{P}<0.05$, between 6.9 and $20.8 \mu \mathrm{mol} / \mathrm{l})$, whereas no significant difference between sorafenib concentrations was observed. Additionally, the growth inhibitory effect was significantly higher in the sorafenib nanoparticle group than in the sorafenib group $(\mathrm{F}=74.988 ; \mathrm{P}<0.05$ in sorafenib nanoparticle group vs. sorafenib group; Table I).

Pharmacokinetics of sorafenib-incorporated nanoparticles. Sorafenib nanoparticles were metabolized rapidly at an early stage, but released slowly thereafter, whereas sorafenib underwent a rapid metabolic process throughout the time. The $T_{1 / 2}$ of sorafenib was $8.22 \pm 2.35 \mathrm{~h}$, while the $\mathrm{T}_{1 / 2}$ of sorafenib nanoparticles was $12.92 \pm 0.57 \mathrm{~h}$. The clearance rate of the nanoparticles was markedly lower than sorafenib, thus the circulating time of the nanoparticles was prolonged to a statistically significant extent ( $F=2.46$; $\mathrm{P}<0.05$; Table II; Fig. 5).

Biodistribution of sorafenib-incorporated nanoparticles in mice. At three weeks following administration, the sorafenib concentration in HCC tissue was $860.00 \pm 152.39 \mathrm{ng} / \mathrm{mg}$ in the sorafenib group, and $2,751.33 \pm 629.6 \mathrm{ng} / \mathrm{mg}$ in the sorafenib-incorporating nanoparticle group, demonstrating statistical significance $(\mathrm{P}<0.05)$. However, in peritumor tissues, the sorafenib concentration in the nanoparticle group $(728.77 \pm 156.39 \mathrm{ng} / \mathrm{mg})$ was lower than in the sorafenib group $(3,030.00 \pm 537.03 \mathrm{ng} / \mathrm{mg})$, with statistical significance $(F=69.47 ; \mathrm{P}<0.05)$. In other tissues, including in the heart, lungs, kidneys, small and large intestine and the spleen, the concentration was also lower in the nanoparticle group $(\mathrm{P}<0.05)$, whereas the concentration in the stomach and muscles was not significantly different between the groups. The high concentration in HCC, yet reduced concentration elsewhere indicates the excellent targeting ability of sorafenib nanoparticles on tumor tissues (Table III; Fig. 6).

Tumor growth inhibition of sorafenib nanoparticles in vivo. HCC tissues presented signs of necrosis to various degrees

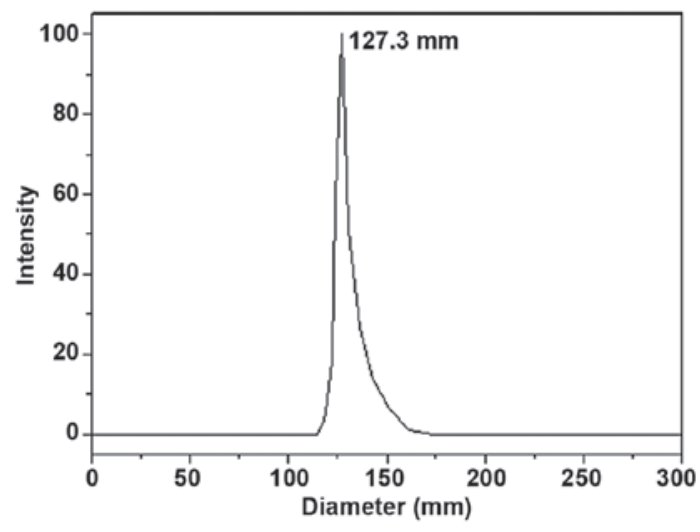

Figure 3. The mean particle size of sorafenib nanoparticles was $127.3 \pm 2.0 \mathrm{~nm}$, with a uniform distribution of particle diameter.

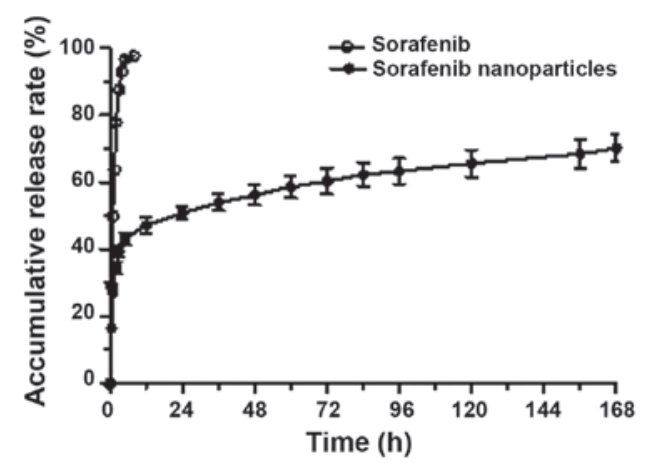

Figure 4. In vitro release curve of sorafenib nanoparticles. Sorafenib nanoparticles released more slowly than sorafenib alone.

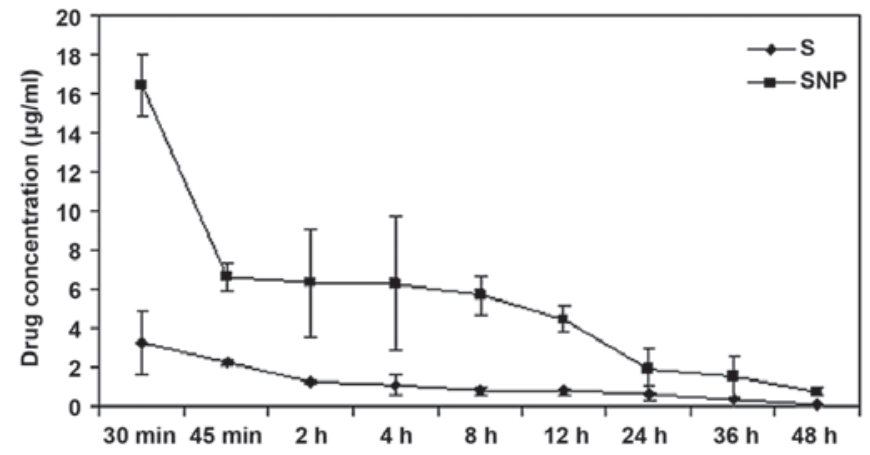

Figure 5. In vivo pharmacokinetics of sorafenib nanoparticles compared with sorafenib. The circulating time of the sorafenib nanoparticles was longer than for sorafenib in vivo. S, sorafenib group; SNP, sorafenib nanoparticle group.

three weeks following the administration of NS, sorafenib or sorafenib-incorporated nanoparticles, with an extent of $29.17 \pm 9.70,46.17 \pm 12.58$ and $63.50 \pm 15.08 \%$, respectively. Compared with NS and sorafenib, the necrosis caused by sorafenib-incorporated nanoparticles was more severe, to a statistically significant extent $(F=20.12 ; \mathrm{P}<0.05$; Fig. 7); the HCC tumor inhibition rates were $-4.87 \pm 2.71,21.58 \pm 3.29$ and $45.78 \pm 7.46 \%$ respectively in each group, indicating that the most potent antitumor effect was associated with sorafenib-incorporating nanoparticles to a statistically significant extent $(F=8.752 ; \mathrm{P}<0.05 ;$ Fig. 8$)$. 
Table II. Pharmacokinetic parameters of sorafenib nanoparticles in vivo (mean \pm standard deviation, $\mathrm{n}=3$ ).

\begin{tabular}{lccc}
\hline Parameter & Unit & Sorafenib & Sorafenib nanoparticles \\
\hline Elimination rate constant & $1 / \mathrm{h}$ & $0.09 \pm 0.02$ & $0.05 \pm 0.00$ \\
Half-life & $\mathrm{h}$ & $8.22 \pm 2.35$ & $12.92 \pm 0.57^{\mathrm{a}}$ \\
Time to peak & $\mathrm{h}$ & $0.08 \pm 0.00$ & $0.08 \pm 0.00$ \\
Concentration of peak & $\mu \mathrm{g} / \mathrm{ml}$ & $5.57 \pm 1.65$ & $453.73 \pm 87.43^{\mathrm{a}}$ \\
Initial concentration & $\mu \mathrm{g} / \mathrm{ml}$ & $7.03 \pm 3.20$ & $992.86 \pm 261.70^{\mathrm{a}}$ \\
AUC $_{0-\mathrm{t}}$ & $\mathrm{h} / \mu \mathrm{g} / \mathrm{ml}$ & $31.02 \pm 6.69$ & $275.39 \pm 26.10^{\mathrm{a}}$ \\
AUC $_{0-\infty}$ & $\mathrm{h} / \mu \mathrm{g} / \mathrm{ml}$ & $31.64 \pm 6.47$ & $289.96 \pm 29.33^{\mathrm{a}}$ \\
Volume of distribution $_{\text {Serum clearance }}^{\mathrm{ml} / \mathrm{kg}}$ & $\mathrm{ml} / \mathrm{h} / \mathrm{kg}$ & $6,066.11 \pm 4,229.43$ & $1,291.06 \pm 93.69^{\mathrm{a}}$ \\
\hline
\end{tabular}

${ }^{a} \mathrm{P}<0.05$ compared with sorafenib. AUC, area under curve.

Table III. The drug concentration of sorafenib nanoparticles in various tissues (mean values \pm standard deviation, $n=3$ ).

\begin{tabular}{lcc}
\hline & \multicolumn{2}{c}{ Concentration following treatment, $\mathrm{ng} / \mathrm{mg}$} \\
\cline { 2 - 3 } Tissue & Sorafenib & Sorafenib nanoparticles \\
\hline Brain & $19.40 \pm 2.16$ & $7.96 \pm 3.85^{\mathrm{a}}$ \\
Heart & $153.67 \pm 25.72$ & $17.90 \pm 1.56^{\mathrm{a}}$ \\
Lung & $292.67 \pm 37.00$ & $92.20 \pm 32.77^{\mathrm{a}}$ \\
Kidney & $289.00 \pm 11.14$ & $61.93 \pm 5.41^{\mathrm{a}}$ \\
Stomach & $293.67 \pm 59.77$ & $241.23 \pm 71.39$ \\
Small intestine & $281.67 \pm 6.43$ & $49.97 \pm 15.17^{\mathrm{a}}$ \\
Large intestine & $457.67 \pm 37.07$ & $37.80 \pm 13.85^{\mathrm{a}}$ \\
Muscle & $81.37 \pm 5.98$ & $64.60 \pm 14.20$ \\
Spleen & $214.33 \pm 17.21$ & $45.47 \pm 12.70^{\mathrm{a}}$ \\
Liver & $3,030.00 \pm 537.03$ & $728.77 \pm 156.39^{\mathrm{a}}$ \\
Tumor & $860.00 \pm 152.39$ & $2,751.33 \pm 629.60^{\mathrm{a}}$ \\
\hline
\end{tabular}

${ }^{\mathrm{a}} \mathrm{P}<0.05$ compared with sorafenib.

\section{Discussion}

Sorafenib is a novel multi-targeted antitumor agent with two antitumor effects: Inhibiting tumor growth directly by suppressing the Raf/MEK/ERK signaling pathway, and indirectly by inhibiting angiogenesis via downregulating VEGFR and PDGFR. In vitro research has demonstrated sorafenib may inhibit HCC cell growth by influencing the cell cycle or inducing apoptosis $(12,13)$. Sun et al (12) observed that sorafenib attenuated the autophagy of HepG2 HCC cells to inhibit proliferation and enhance apoptosis. Liu et al (13) reported that sorafenib inhibited the proliferation of PLC/PRF/5 and HepG2 HCC cells by inhibiting Raf kinase and blocking the MEK/ERK signaling pathway, decreasing the level of cyclin D. In addition, apoptosis was induced by sorafenib via the inhibition of the Raf/MEK/ERK signaling pathway, decreasing the level of elF4E phosphorylation and downregulating the expression of the anti-apoptosis protein Mcl-1 (13).

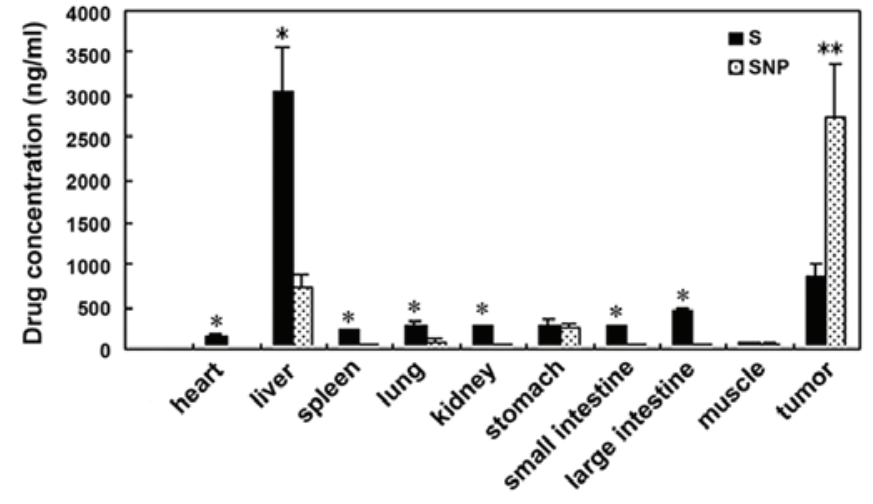

Figure 6. In vivo tissue distribution of sorafenib nanoparticles was measured after three weeks. The sorafenib concentration in SNP was higher than S in tumor tissues. In peritumor tissues, sorafenib concentration in SNP was lower than $\mathrm{S}$. The bars represent the means \pm standard deviation of two independent experiments. ${ }^{*} \mathrm{P}<0.05,{ }^{* * *} \mathrm{P}<0.01$ between $\mathrm{S}$ and SNP. S, sorafenib group; SNP, sorafenib nanoparticle group.

In clinical trials, sorafenib has been demonstrated to prolong the overall survival (OS) time and time to progression of patients with advanced HCC. Using sorafenib to treat 110 HCC patients, Wang et al (14) observed a complete response (CR) in $12.7 \%$ of the patients, partial response (PR) in $14.5 \%$ and stable disease (SD) in $36.4 \%$, with a total effective rate of $63.6 \%$. The median OS and progression-free survival (PFS) times were 10.5 and 5.0 months, respectively; sorafenib significantly increased the long-term OS rate of patients with progressive HCC (14). Abou-Alfa et al (15) reported that in a stage II clinical trial, of the $137 \mathrm{HCC}$ patients receiving sorafenib monotherapy, 3 achieved partial remission (2.2\%), 8 were progressing toward remission (5.8\%), and 46 reached a level of stabilization that was maintained over 16 weeks (33.6\%). The median time to progression (mTTP) was 4.2 months, and the median OS time was 9.2 months. The mTTP of patients positive for phosphorylated (p)-ERK was 178 days, while the mTTP for p-ERK-negative patients was only 46 days, suggesting that the activation of the Ras signal transduction pathway was important to the success of treatment (15). Relatively few HCC patients treated with sorafenib achieved PR or complete remission in the Abou-Alfa et al (15) 


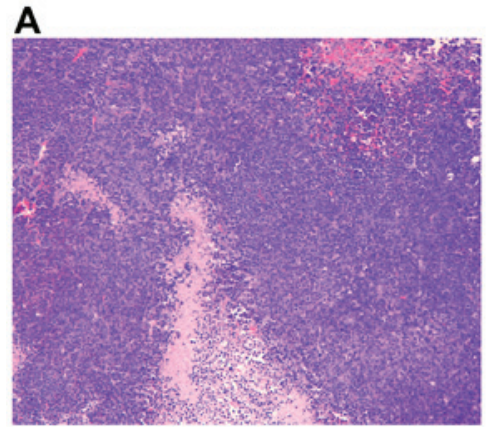

B

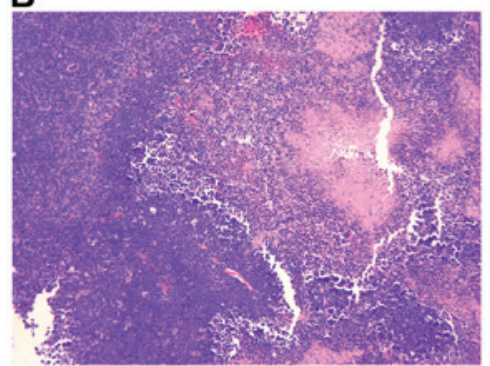

C

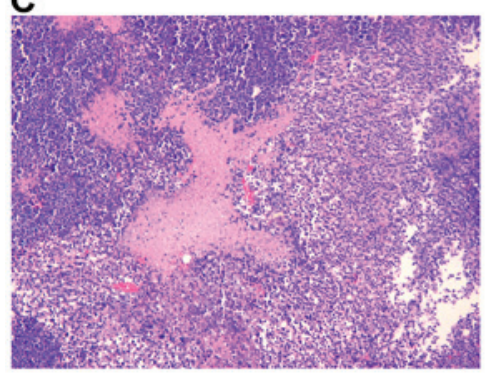

Figure 7. The degree of necrosis of tumor tissues in various groups following drug administration for three weeks. (A) The necrotic area was $29.17 \pm 9.70 \%$ in the normal saline group. (B) The necrotic area was $46.17 \pm 12.58 \%$ in the sorafenib group. (C) The necrotic area was $63.50 \pm 15.08 \%$ in the sorafenib nanoparticles group. Data are presented as the means \pm standard deviation. Hematoxylin and eosin staining, magnification x100.

trial, although it preliminarily indicated that sorafenib's effects are molecularly targeted.

However, due to the inhibition of the Raf/MEK/ERK pathway and direct inhibition of VEGFR-2,3 and PDGFR- $\beta$, sorafenib may interfere with the function of normal cells, leading to adverse effects. Two stage III clinical trials reported that sorafenib was safe and prolonged the one-year OS and PFS rates of patients with advanced HCC from 44 and 47, to 74 and $73 \%$, respectively $(16,17)$. Thus, sorafenib is used as a standard agent for the systemic treatment of advanced HCC. In addition, $\mathrm{Hu}$ et al (18) reported that in patients with $\mathrm{HCC}$ who received a liver transplant, the disease-free survival (DFS) and OS of patients treated with oral sorafenib were significantly improved compared with the control group (DFS, 81.8 vs. $63.6 \%$; OS, 90.9 vs. $72.7 \%$; $\mathrm{P}<0.05)$. The acute rejection rate in the oral sorafenib treatment group and the control group was 13.6 and $18.2 \%$, respectively, and the graft survival rate was 86.4 and $72.7 \%$, respectively, although these differences were not statistically significant (18).

Developing nanoparticle carriers to transport a large bolus of drug molecules into the cytosolic compartments of cancer cells has become a highly active research area in nanomedicine with the development of nanotechnology (19). The properties

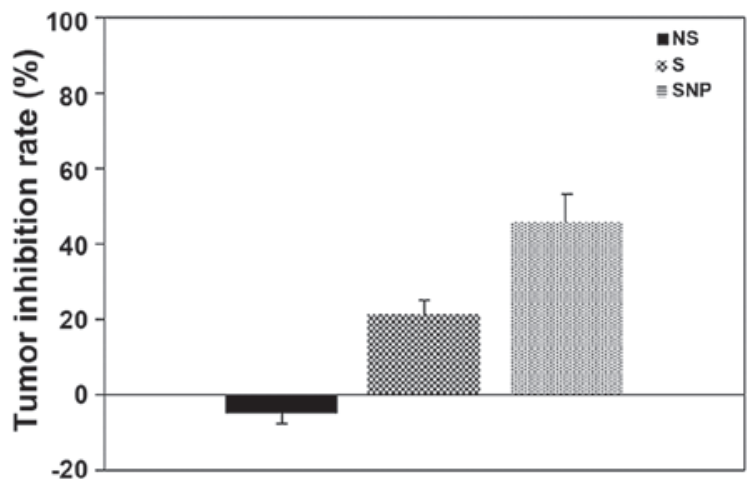

Figure 8. Effect of sorafenib or sorafenib-incorporating nanoparticles on inhibiting the tumor growth in various groups following drug administration for three weeks. The tumor inhibitory rate of sorafenib was higher than that of NS $(\mathrm{P}<0.05)$. The tumor inhibitory rate was the highest in the SNP group $(\mathrm{P}<0.01$ vs. the NS group). The bars represent the means \pm standard deviation of three independent experiments. NS, normal saline group; S, sorafenib group; SNP, sorafenib nanoparticle group.

of nanoparticles that are produced through nanotechnology include a larger specific surface area and increasing numbers of surface atoms, surface energy and surface tension as particle sizes decrease (20). All of these properties endow the nanoparticles with improved absorbability and biological activity. Thus, these particles exhibit many excellent properties for use as drug carriers that alter the distribution patterns of drugs inside the body. These properties enhance the absorption, utilization and stability, improve the targeting effect, sustain the release of drugs, prolong the action time, decrease the necessary dosage, reduce or eliminate side effects and facilitate storage $(19,20)$. In our previous study, ring-opening block copolymers of PEG and PLA were used as drug carriers, and the nanoprecipitation technique was applied to prepare the sorafenib-precipitated nanoparticles (21). Sorafenib nanoparticles were successfully prepared, with a spherical shape and uniform size. The drug loading and the encapsulation efficiency were satisfactory.

In the present study, no significant difference was observed in vitro between the various concentrations of sorafenib in terms of the rate of $\mathrm{H} 22$ cell growth inhibition. By contrast, the inhibition of the growth of $\mathrm{H} 22$ hepatic cells by sorafenib-incorporated nanoparticles at the same concentration was more effective, and the extent of inhibition increased in parallel with the increase in sorafenib-incorporated nanoparticle concentration, indicating that sorafenib-incorporated nanoparticles were efficacious in inhibiting hepatic cancer cell proliferation (Table I). In vivo drug metabolism rates demonstrated that, while sorafenib had a rapid metabolic profile, sorafenib nanoparticles were released and metabolized more slowly and were in circulation for longer than sorafenib (Table II; Fig. 5). The nanoparticle formulation produced a high concentration of sorafenib in HCC tissues, but relatively low concentrations in non-targeted organs (Fig. 6). The tumor necrosis was most severe and the tumor inhibitory effects the most significant following the administration of sorafenib nanoparticles (Figs. 7 and 8). These data suggest that the tumor targeting and antitumor effects of sorafenib nanoparticles were more significant than for sorafenib alone.

In conclusion, sorafenib-incorporated nanoparticles have the desired properties of sustained release and HCC cell/hepatic 
tumor tissue specificity. The sorafenib-incorporated nanoparticles may allow for a change in the route of administration of sorafenib. The selective targeting of hepatic tumor tissues by sorafenib-incorporated nanoparticles may provide a promising strategy to reduce the adverse effects of sorafenib and may perhaps facilitate an increase in the therapeutically tolerable doses of sorafenib, when compared with standard sorafenib administration.

\section{Acknowledgements}

This study was supported by the Major Project of Science and Technology Commission of Shanghai Putuo district (grant no. 2010-B-107). The authors are grateful to Professor Zhang Yan (the Second Military Medicine University, Shanghai, China) for the correction and translation of the manuscript.

\section{References}

1. Matsuda Y, Ichida T and Fukumoto M: Hepatocellular carcinoma and liver transplantation: Clinical perspective on molecular targeted strategies. Med Mol Morphol 44: 117-124, 2011.

2. Tang ZY, Ye SL, Liu YK, Qin LX, Sun HC, Ye QH, Wang L, Zhou J, Qiu SJ, Li Y, et al: A decade's studies on metastasis of hepatocellular carcinoma. J Cancer Res Clin Oncol 130: 187-196, 2004

3. Parkin DM, Bray F, Ferlay J and Pisani P: Global cancer statistics, 2002. CA Cancer J Clin 55: 74-108, 2005.

4. Lyons JF, Wilhelm S, Hibner B, Bollag G: Discovery of a novel Raf kinase inhibitor. Endocr Relat Cancer 8: 219-225, 2001.

5. Wilhelm SM, Carter C, Tang L, Wilkie D, McNabola A, Rong H, Chen C, Zhang X, Vincent P, McHugh M, et al: BAY 43-9006 exhibits broad-spectrum oral antitumor activity and targets the $\mathrm{RAF} / \mathrm{MEK} / \mathrm{ERK}$ pathway and receptor tyrosine kinases involved in tumor progression and angiogenesis. Cancer Res 64: 7099-7109, 2004.

6. Clark JW, Eder JP, Ryan D, Lathia C and Lenz HJ: Safety and pharmacokinetics of the dual action Raf kinase and vascular endothelial growth factor receptor inhibitor, BAY43-9006, in patients with advanced, refractory solid tumors. Clin Cancer Res 11: $5472-5480,2005$.

7. Luo XN, Lu LG, Shao PJ, Hu BS, Li Y, Yu XY and He X: Relationship between sorafenib-associated hand-food skin reaction and efficacy in treatment of advanced hepatocellular carcinoma. Zhonghua Yi Xue Za Zhi 92: 889-893, 2012 (In Chinese).

8. Chu D, Lacouture ME, Fillos T and Wu S: Risk of hand-foot skin reaction with sorafenib: A systematic review and meta-analysis. Acta Oncol 47: 176-186, 2008.

9. Stmmberg D, Awada A, Hirte H, Clark JW, Seeber S, Piccart P, Hofstra E, Voliotis D, Christensen O, Brueckner A and Schwartz B: Pooled safety analysis of BAY 43-9006 (sorafenib) monotherapy in patients with advanced solid tumours: Is rash associated with treatment outcome? Eur J Cancer 42: 548-556, 2006.
10. Robert C, Sofia JC, Spatz A, Le Cesne A, Malka D, Pautier P, Wechsler J, Lhomme C, Escudier B, Boige V, et al: Cutaneous side effects of kinase inhibitors and blocking antibodies. Lancet Oncol 6: 491-500, 2005.

11. Yang CH, Lin WC, Chuang CK, Chang YC, Pang ST, Lin YC, Kuo TT, Hsieh JJ and Chang JW: Hand-foot skin reaction in patients treated with sorafenib: A clinicopathological study of cutaneous manifestations due to multitargeted kinase inhibitor therapy. Br J Demmtol 158: 592-596, 2008.

12. Sun GT, Qiu WH, Shi MM and Chen Z: Sorafenib inhibits human hepatoma cell line HepG2 autophagy. J Surg Concepts Pract 15: 51-55, 2010 (In Chinese).

13. Liu L, Cao Y, Chen C, Zhang X, McNabola A, Wilkie D, Wilhelm S, Lynch $\mathrm{M}$ and Carter C: Sorafenib blocks the RAF/MEK/ERK pathway, inhibits tumor angiogenesis, and induces tumor cell apoptosis in hepatocellular carcinoma model PLC/PRF/5. Cancer Res 66: 11851-11858, 2006.

14. Wang CP, Lu YY, Gao XD, Wang Z, Bai WL, Qu JH, Zeng Z, Zhang M, Chang XJ, Yang YP and Jie FJ: Efficacy of sorafenib for advanced hepatocellular carcinoma and prognostic factors. Chin J Clin Oncol 39: 587-592, 2012 (In Chinese).

15. Abou-Alfa GK, Schwartz L, Ricci S, Amadori D, Santoro A, Figer A, De Greve J, Douillard JY, Lathia C, Schwartz B, et al: Phase II study of sorafenib in patients with advanced hepatocellular carcinoma. J Clin Onco1 24: 4293-4300, 2006.

16. Liovet J, Ricci S, Mazzaferro V, Hilgard P, Gane E, Blanc JF, de Oliveira AC, Santoro A, Raoul JL, Forner A, et al: Sorafenib in advanced hepatocellular carcinoma. N Engl J Med 359: 378-390, 2008 .

17. Cheng AL, Kang YK, Chen Z, Tsao CJ, Qin S, Kim JS, Luo R,Feng J, Ye S, Yang TS, et al: Efficacy and safety of sorafenib in patients in the Asia-Pacific region with advanced hepatocellular carcinoma: A phase III randomized, double-blind, placebo-controlled trial. Lancet Oncol 10: 25-34, 2009.

18. Hu AB, He XS, Tai Q, Zhu XF, Ma Y, Wang DP, Wang GD, Wu LW, Ju WQ and Huang JF: Efficacy and safety of sorafenib in the prevention and treatment of hepatocellular carcinoma recurrences after liver transplantation. Zhonghua Yi Xue Za Zhi 92: 1264-1267, 2012 (In Chinese).

19. Qin JM, Zhang YD, Wang HY, et al: Nanotechnology usage in diagnosis and treatment of liver diseases. Chin J Mod Med 13: 49-52, 2003.

20. Qin JM, Zhang YD, Wang HY and Wu MC: Application and progress of nano-drugs in liver disease. Chin J Hepatobiliary Surg 10: 646-648, 2004 (In Chinese).

21. Qin JM, Yin PH, Li Q, Sa ZQ, Sheng X, Yang L, Huang T, Zhang M, Gao KP, Chen QH, et al: Anti-tumor effects of brucine immuno-nanoparticles on hepatocellular carcinoma. Int J Nanomedicine 7: 369-379, 2012. 